\title{
0 pertencimento ao comum mediático: a identidade em tempos de transição ${ }^{1}$
}

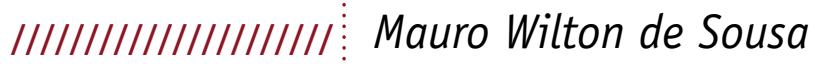

ECA - USP

1. Texto revisado e ampliado, originalmente apresentado no $14^{\text {th }}$ International Culture and Power - Identity and Identification, Ciudad Real, Espanha, abril de 2010, baseado em textos e publicações anteriores do autor, referentes a projeto de pesquisa apoiado pelo CNPQ (Conselho Nacional de Desenvolvimento Científico e Tecnológico). 


\section{Resumo}

O tema do sentimento de pertencimento, cada vez mais presente nos estudos culturais na contemporaneidade, é aqui trabalhado na hipótese de que sinaliza, no contexto da sociedade marcada por exclusões e desigualdades, a busca de identidade diante de um desejado e ausente comum aglutinador. Os meios de comunicação dão visibilidade a essa busca e, por meio de suas ferramentas, possibilitam a expressão pública dessa mesma demanda.

\section{Palavras-chave}

identidade, comum mediático, comunidade, comunicação, exclusão

\section{Abstract}

The theme of the feeling of belonging, increasingly present in contemporary cultural studies, is worked here on the assumption that it signals, in the context of a society marked by inequalities and exclusions, the search for identity before a desired and absent common agglutinator. The means of communication give visibility to this search and through their tools allow the public expression of that same demand.

\section{Key-words}

identity, common media, community, communication, exclusion 


\section{Introdução}

A presença constante das temáticas da inclusão e exclusão social, da emancipação, do pertencimento, da cidadania, da identidade, da diversidade e da diferença, em diferentes ângulos de compreensão da sociedade atual, sinaliza a manutenção, quando não o acirramento, de tensões e conflitos históricos que se manifestam como linguagens dos desencontros, ainda hoje presentes, entre o indivíduo e a sociedade. São questões conceituais e teóricas permeando o mundo da pesquisa científica em diferentes áreas disciplinares, mas são também questões concretas traduzidas não tanto em processos de mudanças socioeconômicas de âmbito estrutural, e sim em práticas de movimentos sociais, de ONGs, de comunidades e de grupos políticos e culturais, indicando descrença em utopias até então vigentes e rejeição aos processos de dominação, à fragmentação do sujeito, às crises do Estado, à heterogeneidade e à pluralidade das formas do ser e do ter, do crer e do viver, enfim, do estar junto social.

São manifestações práticas do cotidiano social e cultural, sinalizando uma sociedade de exclusões crescentes e explicitando, pela necessidade do pertencimento, crises e dificuldades de enraizamentos sociais e políticos, culturais e sociais: uma sociedade que convive, ao mesmo tempo, com processos de fragmentações crescentes da vida individual e coletiva e com processos políticos, econômicos e culturais da globalização. 
É nesse contexto que, hoje, o tema do sentimento de pertencimento manifesta-se cada vez mais, não só em suas áreas disciplinares de origem, sobretudo a antropologia e a política, mas em outras, como a comunicação. Ele se traduz de forma visível, em sentidos e motivações diversos dos de suas raízes, sustentando a busca de participação em grupos, tribos e comunidades que possibilitem enraizamento e gerem identidade e referência social, ainda que em territórios tão diferentes como os da política, da religião, do entretenimento e da cultura do corpo. Em decorrência disso, essas buscas suscitam a quebra tradicional de fronteiras entre o local e o global, o público e o privado, o comum e o individual e a comunidade e a sociedade, gerando tanto hibridismos quanto novas formas de tensão e de conflito.

Atente-se para o fato de que, se é instigante reconhecer a atualidade da temática do sentimento de pertencimento - o mesmo podendo ser aplicado às da inclusão e da emancipação -, é instigante indagar sobre o que a motiva e, sobretudo, sobre o que objetiva o pertencer no contexto de uma sociedade tão desigual quanto globalizada e que ao mesmo tempo está em sua causa e é a sua busca. Pertencer a quê? Incluir-se no quê? Enraizar-se onde? Essas são indagações importantes, fazendo pressupor que a necessidade da busca do pertencimento é tão complexa como a da objetivação que fundamenta essa mesma necessidade.

A temática do sentimento de pertencimento tem ainda sua atualidade e sua complexidade marcadas pela presença dos meios de comunicação atuando no imaginário social, nas diferentes formas de organização da vida individual e coletiva, na delimitação e criação de interesses que os condicionam. Os diferentes media podem, pois, estar atuando como mediação fundamental tanto na construção quanto na caracterização do pertencimento como linguagem de busca de identidade no contexto de um ausente comum aglutinador.

Assume-se aqui, pois, uma perspectiva metodológica de análise sustentada no reconhecimento da dupla mediação entre técnica e sociedade (MIÈGE, 2010, p. 46), perspectiva essa também denominada de sociotécnica. Uma afirmação de Castoriadis, indicada e debatida por Miège, bem aponta o eixo dessa perspectiva: "Mas o conjunto técnico, ele mesmo está privado de sentido, técnico ou qualquer que seja, se o separarmos do conjunto econômico e social." (apud MIÈGE, 2010, p. 9). 


\section{0 que motiva o pertencimento: comunidade e sociedade}

Ao analisar a prática do blog por jovens franceses, Tredan (2009, p. 45) faz observar:

a estrutura hipertextual dos blogs, acompanhada de uma prática centrada sob alguns blogs, implica inevitavelmente a emergência de um sentimento de pertencimento em torno de uma prática. A identidade é, assim, o produto de lutas e controvérsias internas e exteriores ao fenômeno por meio do reconhecimento (...) O fenômeno não se reduz a uma categoria simbólica. Ele acompanha igualmente a apropriação de um conjunto de artefatos técnicos próprios ao seu universo. Esse sentimento de pertencimento se concretiza igualmente no desenvolvimento de metablogs (...) a capacidade reflexiva dos blogueiros se traduz na emergência de um território informacional, a blogosfera.

Essas observações possibilitam introduzir os diversos aspectos que hoje permeiam e atualizam o objeto pertencimento. O tema se vincula historicamente ao de comunidade, no âmbito das ciências humanas e sociais, e hoje ambos são retomados em bases ampliadas de significação e tomam características novas na relação assumida desde décadas passadas na distinção entre comunidade e sociedade. $\mathrm{Na}$ verdade, comunidade e sociedade dicotomizaram formas históricas diferentes de compreensão dos processos de socialização, atribuindo-se à primeira a significação nas formas de organização imediata e visível da vida social e cultural e, à segunda, a relação com a racionalidade que sustenta a estrutura da sociedade. Esses dois contextos, na verdade, explicitavam uma postura sobre a hegemonia que historicamente foi sendo atribuída à compreensão da estrutura da sociedade, diferentemente da que até então, em fases anteriores da modernidade capitalista, coube à organização comunitária da vida social. Daí porque hoje soa muitas vezes estranho e distante o uso do termo pertencimento, sobretudo nas atualizações que vem assumindo, como que descontextualizado historicamente, e soam pertinentes os da inclusão e da exclusão social, ambos se reportando, apesar de proximidades semânticas, a matrizes e tradições históricas e políticas distintas na compreensão das práticas de 
socialização ora na comunidade, ora na sociedade. As dificuldades na ordem da estrutura social se fazem repercutir na atualidade da esfera da organização imediata da vida social, como que ressurgindo a necessidade das comunidades, razão presente na expressão do sentimento de pertencimento.

Mas o conceito de pertencimento, apesar de mantido o termo, tem sua significação ampliada e atualizada na proporção em que igualmente assume o de comunidade, especialmente no estabelecimento de novas fronteiras ante o conceito de sociedade. Há uma afirmação de Touraine (1999, p. 10) que pode indicar esse processo de retomada da relação entre pertencimento e comunidade e desta com a sociedade:
No final do século passado, em plena industrialização do mundo oci- dental, os sociólogos nos ensinaram que passávamos da comunidade, fechada em sua identidade global, para a sociedade, cujas funções se diferenciavam e se racionalizavam. A evolução que nós vivemos é qua- se inversa. Das ruínas das sociedades modernas e de suas instituições saem, por um lado, redes globais de produção, de consumo e de comu- nicação e, por outro lado, uma volta à comunidade. Vimos ampliar-se o espaço público político; ele não se decompõe sob os efeitos opostos dessa tendência à privatização e desse movimento de globalização.

São essas "ruínas das sociedades modernas e de suas instituições" que motivam a retomada do sentido tanto de comunidade como de pertencimento em dimensões que ultrapassam seus sentidos de origem. Atente-se para o fato de que, entre outros autores que aprofundam historicamente a presença e a significação de comunidade, em Weber, pode-se obter o nexo distintivo entre o subjetivo, que motiva o pertencimento, e o objetivo, que também está presente nesse processo de construção do sentimento de pertencimento, como um interesse. Para ele, a motivação social que justifica a comunidade está em um "sentimento subjetivo (afetivo ou tradicional) de partícipes de constituição de um todo", enquanto o conceito de sociedade tinha sua motivação definida pela "compensação de interesses por motivos racionais (de fins ou valores), ou então numa união de interesses com idêntica motivação” (WEBER, 1973, p. 140).

Vista muitas vezes como uma dimensão de "comunidade emocional" (MARTÍN-BARBERO, 2001, p. 41), a afirmação de Weber 
destaca que a motivação subjetiva do pertencimento na verdade repousa na busca de "constituição de um todo", ou seja, naquilo que, como um fim, faz do pertencer um meio e uma necessidade, matriz de algo que se define como um comum. A mediação desse "comum" é que de fato dá sentido a esse "sentimento subjetivo" e implica a sua objetivação.

O mesmo Weber provavelmente já previa que as fronteiras entre comunidade e sociedade são transitáveis quando assegurou que: "a comunidade pode apoiar-se sobre toda espécie de fundamentos, afetivos, emocionais ou tradicionais. O conceito de comunidade é deliberadamente muito amplo e abrange situações de fato muito heterogêneas". Ou ainda quando assegurou que "a imensa maioria das relações sociais participa em parte da comunidade e em parte da sociedade" (WEBER, 1973, pp. 140-143).

Essa afirmação é semelhante ao que Touraine assinalou ao dizer que parte de nós se liga ao espaço público, às normas sociais, e outra, ao hedonismo. Admite-se, pois, que não é difícil apontar que a dimensão subjetiva que motiva o pertencer a um todo é, no caso, o próprio sentimento de pertencimento, acionado de alguma forma pela necessidade já presente nesse todo que é buscado como objetivo-fim. À medida que se ampliam esse todo e a visibilidade e a abrangência do objeto-fim, da motivação e da participação, entra-se na fronteira de comunidade e de sua relação com o todo social mais amplo definido pela sociedade.

As redes de socialização primária representadas pela família, pela religião, pela etnia, pela educação bem indicam o âmbito tradicional e histórico de comunidade-pertencimento. Um todo que agrega, torna visível um contato face a face e a relação de troca de valores, configura a identidade desde a diferença e quase sempre se apoia em bases de territórios não só simbólicos mas físicos: um sentimento de enraizamento tornado visível, quase que dimensionando o "tamanho" desse relacionamento. Só existe comunidade quando se expressa o pertencer a esse todo.

Monteiro (1996, p. 104) assinala a dificuldade de ampliar e ultrapassar o âmbito dessas socializações primárias para chegar ao "pertencimento às coletividades mais abstratas", mais associadas a classes e políticas, no que se refere não mais às formas de organização da sociedade, mas às estruturas que as definem, que as fazem tanto distintas quanto opostas, quando afirma: 
A reivindicação (e o reconhecimento) de direitos supõe, em princípio, que os atores sociais se sintam parte de uma sociedade politica mais abrangente do que aquela definida pelo seu pertencimento a rede de sociabilidades primárias (família, etnia, religião etc.). No entanto, talvez esteja aí um dos nós górdios da questão da democracia do mundo contemporâneo: o enfraquecimento da capacidade dos sistemas democráticos de gerar sentimento de pertencimento a coletividades mais abstratas organizadas em torno do reconhecimento de direitos.

Essa dimensão tradicional de pertencimento-comunidade vê-se hoje ampliada a partir do objeto-fim que a define e a constitui como um todo: comunidade imaginada, comunidade virtual, comunidade de apropriação, comunidade interpretativa, comunidades hermenêuticas, sem mencionar inúmeras expressões que a definem tanto por meio de processos mediáticos quanto nas práticas de movimentos sociais, políticos e culturais, além das redes contemporâneas de relacionamento mediadas por novas tecnologias.

O que Touraine denominou de "ruínas das sociedades modernas e de suas instituições" talvez possa exemplificar e justificar a razão fundamental para a retomada do sentido de comunidade e da significação de pertencimento aí envolvidos. Primeiro, no contexto mais amplo da própria modernidade ainda hoje vigente. Por outro lado, na expressão da fragmentação da rede de instituições sociais básicas (envolvendo a família, a igreja, a escola, bem como o Estado e os partidos), a fragmentação do homem como sujeito e ator social diante de utopias nem sempre materializadas são, entre outras, motivações que sugerem a busca de novas identidades coletivas e individuais que se materializem no espaço visível das relações sociais como outras formas de coadunar (e referenciar) a liberdade com a fluidez de valores e de condições de exercê-la. A perda das referências coletivas e das utopias leva à busca de novas formas de enraizamento e desenraizamento, embora na oscilação de compromissos, normas e valores.

Assim, a dimensão simbólica compartilhada em práticas que geram identificação, se é um traço constitutivo da comunidade, hoje não se vincula necessariamente a territórios físicos delimitados, não se define em um "tamanho", não pressupõe lugares nem o contato face a face, mas resguarda-se na materialidade visível de interesses sendo compartilhados e que envolvem participação, as- 
segurando-se como linguagem de pertencimento (PAIVA, 1998, p. 68). Comunidade se coloca como expressão de compartilhamento.

Em passado não muito distante, essa relação foi sinalizada pela razão iluminista com possibilidades emancipatórias advindas sobretudo de mudanças estruturais desejadas na produção socioeconômica, em um contexto histórico da modernidade capitalista e em uma de suas fases mais desenvolvidas e provocativas, graças não só à industrialização emergente como às promessas advindas do desenvolvimento técnico e cientifico.

Silverstone (2002, p. 185) lembra que:

as comunidades sempre tiveram uma composição simbólica e também material. Elas são definidas pelas minúcias da interação cotidiana, assim como pela efervescência da ação coletiva (...) sem sua dimensão simbólica não são nada. Sem seus significados, sem crença, sem identidade e identificação, não há nada: nada a que pertencer, de que participar, nada para compartilhar, promover, e nada para defender.

Mas é o mesmo Silverstone que lembra que, se as comunidades são definidas não só pelo que é compartilhado mas também pelo que é distinguido, a comunidade é "essencialmente uma reivindicação por diferença” (2002, p. 187), é o exercício do "estar junto social” e, hoje, com as possibilidades da conectividade tecnológica, o "estar com”, como exercício da diferença (HALL, 2003, p. 60), ou mesmo a "diferença como unidade da identidade" (HALL, 1999, p. 62).

Esse exercício, segundo Touraine (1999, p. 23), poderia ser visto como a própria manifestação da constituição do sujeito:

em um mundo em mudança permanente e incontrolável, o único ponto de apoio é o esforço do indivíduo para transformar experiências vividas em construção de si como ator. A esse esforço do indivíduo para ser um ator é que chamo de sujeito, que não se confunde nem com o conjunto da experiência nem com um princípio superior que guiaria o indivíduo e lhe daria uma vocação. O sujeito não tem outro conteúdo que a produção dele mesmo.

Nesse contexto, perde-se a rigidez de normas e de condições de pertencimento, e o enraizamento e o desenraizamento se expressam em processos de mutação constante, chegando-se a essa quebra de 
fronteiras entre o local e o global, o indivíduo e a sociedade, o público e o privado, ao que Bauman (2003, p. 66) atribui às comunidades estéticas, ou seja, a possibilidade de uma natureza superficial, perfunctória e transitória dos laços que surgem entre seus participantes. Se pertencimento também é expressão marcante de uma crise de nossa era, é tanto mais buscado à medida que a sociedade não provê condições de realizá-lo, e identidade e pertencimento se confundem. Expressam um estar junto em crise como se depreende da afirmação de Martín-Barbero (2001, p. 40):

\begin{abstract}
Novas maneiras de estar juntos, cuja ligação não provém de um território fixo nem de um consenso racional e duradouro, mas da idade e do gênero dos repertórios estéticos e dos gostos sexuais, dos estilos de vida e das exclusões sociais. E que, diante dos tempos longos, mas também de rigidez das identidades tradicionais, amalgamam referentes locais com símbolos de vestuário ou linguísticas desterritorializados, num redelineamento das fronteiras políticas e culturais que traz à tona o arbitrário artificialismo das demarcações que foram perdendo a capacidade de nos fazer sentir juntos.
\end{abstract}

Esse caráter efêmero e transitório que as comunidades podem assumir não invalida o sentimento que motiva buscá-las, a procura de conexão, de um pertencer e "estar com”, ainda que com as possíveis características do que Castells denomina de "Mass Self Communication (intercomunicação individual", 2006) ou que Flichy criticamente denomina de "comunicação de massa individual" ou "sociedade do individualismo conectado" (2004). Essas observações levam necessariamente ao questionamento do lugar do sujeito, como apontado por Touraine, e o lugar do individualismo conectado.

Enfim, a motivação que justifica o pertencer, atentos ao fato de que a identidade se reporta ao que Weber já assinalara quanto à comunidade como sustentada em fundamentos afetivos, emotivos ou tradicionais, "é deliberadamente muito ampla, e portanto abrange situações de fato muito heterogêneas" (WEBER, 1973, p. 141). 


\section{0 que objetiva o pertencimento}

Ainda que sob contextos conceituais e teóricos distintos, termos como "constituição de um todo" (WEBER, 1973), "identificações coletivas" (TOURAINE, 1999), “vontade comum” (TÖNNIES, 1973), "destino comum” (TELLES, 1999 e Paiva, 1998) e, mais usualmente, "mundo comum" indicam a objetivação que a relação social expressa como fim, ou seja, a própria razão de ser da comunidade.

Pressupõe-se, pois, que as dimensões de comum e de público podem se confundir, isto é, há uma objetivação que se coloca como sendo compartilhada e socializada, tornada pública, matriz geradora do sentimento de pertencimento. É uma dimensão de público-comunidade que não se restringe à concepção de Tönnies (1973, p. 97) quando diz que:

tudo que é confiante, intimo, que vive exclusivamente junto é compreendido como a vida em comunidade; a sociedade é o que é público, é o mundo. Ao contrário, o homem se encontra em comunidade com os seus desde o nascimento, unido a eles como no bem como no mal. Entra-se na sociedade como em terra estrangeira.

Talvez a acepção de Silverstone (2002, p. 182) seja aqui ainda mais indicativa:

sonhamos com comunidade (...) com o comum e as realidades partilhadas que estão na base dela. Sonhamos com uma vida com os outros, com a segurança de lugar, familiaridade e cuidado.

Se o comum é o que motiva o estar junto, o que gera a confluência de olhares e práticas desde o cotidiano, como assinalado por Silverstone, há um bom número de outras questões para a compreensão desse comum aglutinador e que acabam sendo fatores para a sua relativização ou para a sua percepção ampliada nos dias atuais. 


\section{0 comum enquanto uma linguagem}

A dimensão simbólica envolvendo valores e interesses a serem compartilhados, constituindo-se em linguagem, em sentidos de vida, talvez seja o elemento fundamental que define o comum. O mundo simbólico a ser compartilhado é a própria representação que gera o comum:

a representação inclui as práticas de significação e os sistemas simbólicos por meio dos quais os significados são produzidos, posicionando-os como sujeito. É por meio dos significados produzidos pelas representações que damos sentido à nossa experiência e àquilo que somos (Woodward, 2000, p. 17).

A materialidade e a visibilidade com que são publicizados, nem sempre face a face, nem sempre em lugares físicos, mas que geram identificação, motivam práticas, sintonizam o diverso, são o elo que motiva o pertencer e envolve o participar, o compartilhar. É então que se dá o enraizamento de práticas, o sentido de comunidade se alicerça no de compartilhar. A carência dessas representações traduzidas em símbolos que levem a identificação a um só tempo justifica o sentimento de pertencimento na atualidade e a objetivação aí presente como busca: linguagens que motivam o aglutinar, o enraizar em um mundo comum. As observações acima de Tredan encontram aí respaldo significativo.

Poder-se-ia questionar se essa busca de um comum coletivo é suficiente para definir o todo que motiva o estar junto. Questionar se essa não é uma perspectiva de visão orgânica da sociedade, isto é, a partir da função das partes.

É o que se depreende das perspectivas de Park e Burguess (1973, p. 145), quando indicam:

embora seja verdade que a sociedade tem esse duplo aspecto, o individual e o coletivo, a suposição desse volume é que a pedra de toque da sociedade, o que distingue uma mera coleção de indivíduos de uma sociedade não é a consciência comum, mas a ação coletiva (...) Essa existência de um fim comum é talvez tudo que pode ser legitimamente incluído na concepção 'orgânica' quando aplicada à sociedade. 


\section{0 comum na pluralidade e na diversidade do tempo social}

Essa dimensão simbólica sugere que esse comum que agrega, sustentado em valores e interesses compartilhados, coloca-se no tempo, isto é, não é fixo, não é permanente, nem como elemento agregador do objeto-fim socializado nem como motivação enquanto forma, sempre presente para as pessoas. A temporalidade que permeia a vida das pessoas pode ver nesses valores simbólicos motivos de sintonia ou não, em um certo tempo, e não em outro. Esses valores simbólicos podem tanto exercer um significado agregador em um tempo, fator de enraizamento sugerido e ao mesmo tempo buscado, como podem não ter a durabilidade de uma significação. A pluralidade da cultura e das temporalidades em sua vivência bem como a desigualdade social dão ideia da diversidade com que o comum se realiza na vida social.

Essa mutabilidade presente tanto no comum proposto quanto na motivação com que é buscado pode bem apontar o caráter de não permanência das comunidades imaginadas, especialmente para os que dela partilham. A atualidade da crise de pertencimento, enquanto objetivações que o motivem, pode estar presente hoje, por exemplo, na crise de identificações culturais apoiadas na concepção de nação, suficientes ontem para agregar como sendo um comum e, em seguida, insuficientes como fator de identificação.

Para Hall (1999, p. 58), uma cultura nacional vista como uma comunidade imaginada tem três conceitos ressonantes: as memórias do passado, o desejo por viver em conjunto, a perpetuação da herança. A mutação ou a erosão desses suportes implica a possibilidade de a cultura nacional deixar de gerar identificações, portanto, pertencimento, propiciando a busca de outros valores aglutinadores. Hockheimer e Adorno (1973, p. 151) apontam para essa mutabilidade já na percepção das motivações que justificam o todo-comum da própria sociedade:

a sociedade moderna, como um todo, já deixou de ser acessível à experiência imediata, perceptível em sua totalidade e em suas motivações - no sentido em que poderia sê-lo uma sociedade agrária, pura ou mesmo uma antiga economia corporativa urbana. 
Não é diferente então apontar que essa mutabilidade do tempo social se associa ao que Touraine já assinalara como ligado à crise do próprio contexto da modernidade. Não é igualmente diferente do pensamento de Arendt ao dizer que, na modernidade, a perda da religião, das tradições e da autoridade do passado é "equivalente à perda do fundamento do mundo", do "orientar-se no mundo," em que "todas as coisas, a qualquer momento, podem se tornar praticamente qualquer coisa" (apud TELLES, 1999, p. 30).

\section{0 comum envolve a igualdade e a diferença}

Se o comum como um todo simbólico agregador - étnico, religioso, político etc. - pode ser mutável tanto na temporalidade com que é proposto e visualizado quanto na temporalidade dos que o demandam, ele também envolve necessariamente a identificação que gera a identidade, bem como a diferença que não o pressupõe agregador.

A alteridade necessária na vida social parte do pressuposto da diversidade que a motiva e que gera a troca entre diversos. Paiva (1998, p. 90) lembra que

o simples estar junto não significa partilhar da experiência do outro, até por que, de acordo com essa perspectiva, não é apenas a proximidade que define. A experiência do outro implicaria uma atitude recíproca de interioridade.

Assim, o reconhecimento do outro, baseado na diversidade dos agentes, é que possibilita a identidade, o olhar de reconhecimento da distinção. Identidade e diferença se compõem não só como presenças buscantes que formam um comum-comunidade mas também como indicadores de aceitação de um comum-comunidade agregador de valor. A identidade é exatamente a necessidade de posicionar-se ante o diverso, sobretudo ante o sólido visível em um contexto de instabilidades. Identidade-comunidade levam ao que Bauman chama de necessidade de segurança (2003). A igualdade não se confunde com a aniquilação da diferença, mas apenas acentua que o comum é igual para os que sendo diversos se identificam com esse mesmo comum. A pluralidade se mantém com a aceitação da diversidade, e não com sua supressão, um enfrentamento 
desde o comum, e não apesar dele. Na prática, a questão se desloca para a igualdade-justiça (SEMPRINI, 1999, pp. 157-160).

A diversidade, como marca da contemporaneidade, e, ao mesmo tempo, a busca de sua superação gerariam o que motiva o movimento de enraizamento-desenraizamento que sustenta a necessidade de pertencimento na contemporaneidade. É bem verdade que uma cultura comum na advertência de Williams não é em nenhum nível uma cultura igual,

uma efetiva comunidade de experiência e sua qualidade dependem com igual certeza do conhecimento de uma prática de igualdade entre os cidadãos. Os vários tipos de desigualdade que ainda dividem a comunidade em que vivemos tornam difícil ou impossível a comunicação eficaz. Não dispomos de uma genuína experiência comum, a não ser em raros e perigosos momentos de crise. Necessitamos de uma cultura comum. Necessitamos dela não para dispor de uma abstração, mas porque não sobrevivemos sem o seu auxílio (1969, p. 326$)$.

Essas diferentes conotações que o comum assume trazem na contemporaneidade a presença, como já assinalado, de que ele não é permanente, não é igual, envolve a diferença e que não se coloca como comum único. Aflora-se a questão da monocultura impossível e da convivência com o multiculturalismo, com a diversidade assumindo a marca contestatória, mais na esfera das comunidades do que na esfera mais ampla da sociedade, como a globalização acaba propondo. Em um mundo marcado pela "ruínas da modernidade de suas instituições" (TOURAINE, 1999, p. 10) pelo fluxo migratório de valores, de culturas e economias, mestiçagem cultural se confunde com multiculturas. A identidade pode estar na diferença, o comum, no diverso, e o plural se mostra único como plural.

É nesse sentido que se coloca que a crise de representação que marca a contemporaneidade se desloca dos ideais da sociedade global para os da comunidade local, em um fluxo nomádico sem um equilíbrio à vista:

uma parte de nós mesmos mergulha na cultura mundial, enquanto a outra parte, privada de um espaço público onde se formaria e se aplicariam normas sociais, se fecha no hedonismo ou na busca de pertenças imediatamente vividas (Touraine, 1999, p. 14). 
Não é diferente a colocação de Semprini (1999, p. 132) ao afirmar que:

é preciso considerar na definição de um espaço público multicultural a configuração que aí assumem os conflitos sociais e a questão do poder. Os conflitos não se resumem mais exclusivamente na luta pelo controle dos recursos naturais, dos meios de produção, das riquezas, ou mesmo do poder político tradicional. Eles se localizam mais sobre o controle da produção e da distribuição dos significados e dos símbolos sociais.

É esse conflito de multiculturas que na verdade busca na esfera local enraizamentos individuais e, na esfera social mais ampla, gera os conflitos em torno da sua hegemonia - étnica, política, religiosa etc. -, frente a uma economia que se pressupõe suficientemente globalizada e hegemônica para tanto ignorá-lo quanto dominá-lo.

A noção generalizada de exclusão, de crise de pertencimento, de ausência de referências sólidas faz do fluido e do estável sua marca nas acepções de Vattimo (1992) e de Hall (1999).

É em uma perspectiva crítica que Dagnino (1994, p. 109) vai além quando aponta que mais importante do que pertencer ou participar de um comum já estabelecido é participar de sua própria definição:

a nova cidadania transcende uma referência central do conceito liberal, que é reivindicação de acesso, inclusão, membership, pertencimento (belonging) ao sistema político, na medida em que o que está de fato em jogo é o direito de participar efetivamente da própria definição desse sistema, o direito de definir aquilo no qual queremos ser incluídos, a invenção de uma nova sociedade.

\section{Práticas mediáticas e pertencimento: linguagens}

É de Williams (1969, p. 322) a indicação de que toda teoria da comunicação é uma teoria da comunidade. O comum que as une é o relacionamento humano, sob diferentes formas e motivações, no tempo e no espaço históricos da vida social. 
Nesse processo de alteridade social, Touraine (1999, p. 84) é incisivo quando assinala que o processo da comunicação não antecede um outro, aquele que motiva a própria constituição das pessoas como sujeito:

muitos dão importância primordial à comunicação. Penso, ao contrário, que a relação consigo mesmo preside o relacionamento com os outros. É um princípio não social que preside as relações sociais, de sorte que, depois de um longo período durante o qual se tentou explicar o social somente pelo social, de novo reconhecemos que o social repousa sobre o não social e não se define a não ser pelo lugar que concede ou recusa esse princípio não social que é o sujeito.

Talvez se possa afirmar que a comunicação se explicita como fundamento na vida das pessoas exatamente no contexto da experiência de constituição do sujeito. Assim, observa-se que o papel contemporâneo da comunicação torna-se cada dia mais reconhecido à medida que a própria sociedade se envolve na experiência de construção do sujeito.

Os processos que delimitam a fragmentação das condições da vida, atuando junto com o processo da globalização na esfera da produção, necessariamente possibilitam múltiplas dimensões da crise entre o indivíduo e a sociedade, o sujeito individual e o coletivo, impedindo a sutura dessa fragmentação (Ruiz, 2003). A comunicação hoje, talvez muito mais do que no passado, ainda que se colocando eventualmente de forma hegemônica ante mutações nos quadros das instituições sociais básicas, desenvolve sobretudo um papel de mediação e, por isso mesmo, estratégico e, mais, politicamente importante na contemporaneidade, na relação entre as pessoas, e destas com a sociedade.

Vattimo chega a propor que a modernidade, como que assumindo a perspectiva de uma história unitária, termina e dá lugar à pós-modernidade, exatamente com o advento da sociedade da comunicação generalizada: "A impossibilidade de pensar a história como um curso unitário (...) é também, e talvez mais, o resultado do nascimento dos meios de comunicação de massa" (1992, p. 10).

Esse lugar estratégico dos media na contemporaneidade, configurando-lhe de modo especial o papel de mediação, assume diferentes instantes no espaço histórico social, especialmente na 
relação que faz do pertencimento um significado que na contemporaneidade cada dia mais se evidencia.

A primeira dessas mediações se desenvolve quando os media atuam no mundo simbólico, intermediando valores e interesses, no próprio conteúdo que dá sentido à comunicação. A relação social se estrutura desde a representação que configura esse mundo simbólico e é nele e a partir dele que a materialidade da vida busca sua objetivação, traz demandas individuais e coletivas, exige processos tanto de tensão e de conflitos quanto de negociação. Há uma afirmação de Martín-Barbero (2001, p. 31) significativa para dar conta desse processo, especialmente sob a ótica da recepção, no quadro dos agentes consumidores atores do processo comunicacional mediático:

é impossivel saber o que a televisão faz com as pessoas se desconhecemos as demandas sociais e culturais que as pessoas fazem à televisão. Demandas que põem em jogo o contínuo desfazer-se e refazer-se das identidades coletivas e dos modos como elas se alimentam e se projetam sobre as representações da vida social que a televisão oferece.

Mediação enquanto espaço de objetivação de demandas é também espaço de negociação, como que indicando presença na construção de um espaço público mediático sustentado na diversidade:

desde os anos 6o, os veículos de comunicação de massa e principalmente a televisão têm disponibilizado uma enorme quantidade de informações sobre a vida, valores, estilos de vida de grupo que ignoravam tudo ou quase tudo a respeito de outros grupos. Se essa vinculação de informação não homogeneíza as diferenças, ela pelo menos garante sua notoriedade e conscientizou-se de sua existência. Longe de ser simplesmente um espelho, os meios de comunicação tornaram-se um lugar onde se elaboram, se negociam e se difundem os discursos, os valores e as identidades. Ao 'oferecer' uma apresentação multicultural da sociedade, os meios de comunicação contribuem para sua definição (Semprini, 1999, p. 123).

Vattimo entende que o nascimento dos media na contemporaneidade é responsável pela percepção da impossibilidade de pensar o curso da história como unitário, desenvolvendo desde então um papel importante na dissolução dos pontos de vista centrais, ou das 
grandes narrativas, propiciando, ao invés de uma massificação das visões de mundo, pensada por Adorno, o contrário, "a explosão e a multiplicação de visões de mundo" (1992, p. 11).

É bem verdade que há um espaço público que dá visibilidade às questões, tornando-as um comum mediático: "o público se configura como o comum", o mundo próprio a todos, o que implica, como a própria Arendt já afirmara, que ela seja ao mesmo tempo "o difundido, o publicitado" entre a maioria (apud Martín-Barbero, 2001, p. 44). Essa é a perda de um mundo a que também Arendt se refere no sentido da perda de referências cognitivas e valorativas de um horizonte comum e de uma interlocução possível (apud TELLES, 1999, p. 38).

Essas considerações apontam que a dimensão de comum, na perspectiva que hoje atualiza o conceito de comunidade, necessariamente também envolve a atualização do comum-público, na articulação com o espaço público na contemporaneidade. Essas mesmas considerações sinalizam que a mediação do processo comunicacional hoje, talvez mais do que ontem, se coloca como fundamental tanto para expressar o diverso e o plural quanto para sinalizar a busca incessante de sua visibilidade, como que redimensionando pelo espaço público mediático e os modos contemporâneos de dominação e negociação do estar junto social, da relação que motiva o eu e o outro ou dos conflitos que o sustentam.

$\mathrm{O}$ advento das tecnologias interativas, ferramentas e dispositivos que possibilitam a cibercultura, redimensionou as condições de expressão e publicização desse estar junto/estar com. O contexto de uma sociedade moderna em transição se coloca ao lado dessas novas condições das tecnologias interativas, oferecendo um cenário tão novo quanto complexo para assinalar distintos e simultâneos processos de mutação em curso. Em consequência, possibilitam novos olhares não só sobre o espaço público, ou sobre a crescente significação das práticas de socialização mas também oferecem elementos para uma indagação quanto à mutação da própria comunicação como processo social.

Essas indagações estão presentes, por exemplo, em Beaud (1985), que centraliza a análise do pertencimento na constatação de que, na sociedade contemporânea, o social vem encontrando sua autonomização, sua força e sua secularização. À medida que aumentam as demandas sociais e à medida que o Estado se mostra incapaz dc atendê-las, não só os atores institucionais vivem o conflito 
das demandas propostas e não atendidas, como toda a estrutura do político passa a depender desse conflito gerado a partir do social, salientando-se, então, a necessidade da estratégia da negociação nas sociedades democráticas. É a esse processo entre o social e o político que Beaud denomina de ampliação de fronteiras: o social permeia o político ao mesmo tempo em que o cultural se expressa como constituinte da esfera pública e da esfera privada, familiar, indo até as novas formas de socialização, que se colocam como a própria expressão do conflito, ou seja, das bases da democracia. As possibilidades e a direção do esforço democrático ficam atreladas a essa capacidade de encaminhamento das tensões sociais, aumentadas pela atuação crescente do mercado, num jogo em que o social, o Estado e o mercado se colocam como principais agentes. Então, diz Beaud, "cada um é chamado a pensar enquanto indivíduo social em relação às novas formas de pertencimento social e de sua integração" (1985. p. 131).

Indagações e perspectivas estão igualmente em Lemos e Levy (2010, p. 59) quando indicam que:

as funções pós-massivas irão criar ferramentas de conversação e disseminação da opinião pública ampliando a própria ideia de esfera pública. Assim, com a expansão da televisão, do rádio e dos meios impressos e com a convergência da informática-telecomunicação, o surgimento de redes telemáticas planetárias e a consequente e paulatina liberação do polo da emissão, criam-se condições para a emergência de uma cidadania planetária em uma nova esfera pública mundial.

É nesse contexto, apoiados em diferentes questões ligadas aos novos usos da Web social, como a apropriação individual de produtos massivos, indicada por Castells como 'medias de massa individuais', que Millerand e Proulx indagam não apenas sobre a emergência de um novo tipo de mídia, mas "em que medida estar-se-ia diante de uma mutação da comunicação mediática” (2010, p. 24). 


\section{Bibliografia}

ADORNO, T. W. \& HORKHEIMER, M. (orgs.). Temas básicos da sociologia. São Paulo: Cultrix, 1973.

BAUMAN, Z. Comunidade. Rio de Janeiro: Jorge Zahar, 2003.

BEAUD, P. Medias, mediations et mediateurs dans la societé industrielle. Grenoble: These doctorat d'Etat, 1985.

CASTELLS, M. A era da intercomunicação. Tradução de: Marcia Macedo. Paper. São Paulo: 2006.

DAGNINO, E. "Os movimentos sociais e a emergência de uma nova noção de cidadania”. In: DAGNINO, E. (org.). Anos 9o: política e sociedade no Brasil. São Paulo: Brasiliense, 1994.

FLICHY, P. L. "Individualism connecté entre la technique numerique et la societé”. In: Revue Réseaux. Paris: Hermès Lavoisier, n. 124, pp. 17-51, 2004.

HALL, S. A identidade cultural na pós-modernidade. Rio de Janeiro: DP\&A, 1999. Da diáspora, identidades e mediações culturais. Belo Horizonte: Editora UFMG, 2003.

LEMOS, A. \& LEVY, P. O futuro da internet. São Paulo: Paulus, 2010.

MARTÍN-BARBERO, J. “O medo da mídia”. In: LADISLAU, D. et al. Desafios da comunicação. Petrópolis: Vozes, 2001.

MIÈGE, B. A sociedade tecida pela comunicação. São Paulo, Paulus, 2010.

MILLERAND, F. \& PROULX, S. "Le Web Social, au carrefour de multilples questionnements". In: RUEFF, J. et al. Web Social: mutation de la communication. Québec: Presses de l'Université du Québec, 2010.

MONTEIRO, P. "Cultura e democracia no processo de globalização". Rev. Novos Estudos. São Paulo: Cebrap, n. 44, mar. 1996.

PAIVA, R. O espírito comum. Petrópolis: Vozes, 1998.

PARK, R. \& BURGUESS, E. W. “Comunidade e sociedade como conceitos analíticos”. In: FERNANDES, F.. Comunidade e sociedade. São Paulo: Biblioteca Universitária, 1973.

RUIZ, C. B. Os paradoxos do imaginário. S. Leopoldo: Unisinos, 2003.

SEMPRINI. A. Multiculturalismo. Bauru: Edusc, 1999.

SILVERSTONE, R. New media and community. Paper. Londres: London School of Economics and Political Science, set. 1999. 
Porque estudar a mídia? São Paulo: Loyola, 2002.

SOUSA, M. W. "O comum mediático e o pertencimento nas práticas de recepção em comunicação". In: Rev. Novos Olhares. São Paulo, n. 11, 2003.

TELLES, V. "Política e espaço público na constituição do mundo comum: notas sobre o pensamento de Hanna Arendt". In Telles, V. Direitos sociais. Belo Horizonte: UFMG, 1999.

TÖNNIES, F. “Comunidade e sociedade como entidades típicoideais". In: FERNANDES, F. Comunidade e sociedade.

São Paulo: Biblioteca Universitária, 1973.

TOURAINE, A. Poderemos viver juntos? Iguais e diferentes. Petrópolis: Vozes, 1999.

TREDAN, O. “Do weblog aos blogs de adolescentes: itinerário de um percurso de pesquisa sobre a prática de blog pelo público jovem”. In: Ver. Comunicare. São Paulo:

Cásper Líbero, vol. 9, n.1, pp. 41-59, 2009.

VATTIMO, G. A sociedade transparente. Lisboa: Relógio d'Água, 1992. . "Estruturas de sentido". In: WILLIANS R. Marxismo e literatura. Rio de Janeiro: Jorge Zahar, 1979.

WEBER, Max. "Comunidade e sociedade como estruturas de socialização”. In: FERNANDES, F. (org.). Comunidade e sociedade. São Paulo: Biblioteca Universitária, 1973.

WILLIANS, R. Cultura e sociedade. São Paulo: Nacional, 1969. . "Estruturas de sentido". In: WILLIANS R. Marxismo e literatura. Rio de Janeiro: Jorge Zahar, 1979.

WOODWARD, K. "Identidade e diferença: uma introdução teórica e conceitual”. In: SILVA, T. T. Identidade e diferença. Rio de Janeiro: Vozes, 2000. 